\title{
Gender Inequality and Role-strained among Male Nursing Students in Selected Nursing Institution, Lagos, Nigeria
}

\author{
Florence F. Folami \\ Correspondence: Florence F. Folami, Ph.D., MSN, MSPH, RN, RM, IBCLC, Department of Nursing Science, Faculty of \\ Clinical Science, University of Lagos, Idi-Araba, Lagos, Nigeria.
}

Received: April 23, 2017

doi:10.11114/jets.v5i6.2435
Accepted: May 21, $2017 \quad$ Online Published: May 22, 2017

URL: https://doi.org/10.11114/jets.v5i6.2435

\begin{abstract}
Gender discrimination remains problem in the world as a whole and unfortunately, nursing profession is not immune to this problem. Gender discrimination is rejection or restriction made on the basis of socially constructed gender roles which prevents a person from relishing full human rights. Role strain has been defined as when an individual is likely to experience tension in coping with the rations of dissenting roles. Role strain can occur when the men in nursing are observed by lecturers and peers to occupy a female role distinct with their masculine gender which may lead to diminishment of their individual contribution. Simple random sampling method was used to select nursing institutions that was included in the study and convenience sampling method was used to select the respondents that partook in the study. The study population is male nursing students from 200 level-500 level of the selected nursing institutions. A questionnaire including measures of gender role identity and perceived gender relevance of careers was administered to 205 male student nurses from three nursing institutions. The results showed that $32 \%$ of the respondents had not experienced gender bias during nursing school, whereas $68 \%$ reported gender bias from the lecturers and the nursing staff. This study has implications for nursing profession that address the current predicament in the nursing field caused by discrimination and social isolation that man face. Therefore, Nursing and Midwifery council of Nigeria should develop a strategic plan to addresses the eradication of discrimination and racism in and by the nursing profession.
\end{abstract}

Keywords: gender discrimination, role strain, tokenism, advising, gender diversity

\section{Introduction}

Discrimination is defined as making a difference in handling or favor on a class or categorical basis while disregarding individual merit (Lerardi, Fitzgerald, \& Holland, 2010). Love (2010) also defined discrimination as acting on the basis of prejudice and the denial of equal opportunity for education, employment, promotions and health care. Discrimination is not always easy to prove, however, its consequences are quite concrete. Women have led the field of nursing since the beginning of the profession and societal views have changed regarding gender roles and the nursing profession. As the coordinator of a department of nursing science, I have a strong interest in the male student perception of nursing as a female-dominated arena. My interest was further nettled by interactions I had with male nursing students in my department. Connected to this interest is the question of what do nursing lecturers and administrative staff know how male students feel in a female normative profession.

Gender discrimination remains a problem in society as a whole and unfortunately, the nursing profession is not immune to this problem (Shelton, 2012). Gender discrimination is exclusion or restriction made on the basis of socially constructed gender roles which prevents a person from enjoying full human rights (Ellis, Meeker \& Hyde, 2006). A gender role is a set of societal norms dictating the types of behaviors which are generally considered acceptable, appropriate, or desirable for people based on their actual or perceived sex or sexuality. Gender roles are usually centered on conceptions of femininity and masculinity, although there are exceptions and variations (Stroshine \& Brandl, 2011).

Role strain has been defined as when an individual is likely to experience tension in coping with the requirements of incompatible roles (Stroshine \& Brandl, 2011). Role strain can occur when the men in nursing are perceived by lecturers and peers to occupy a female role distinct with their masculine gender which may lead to the minimization of their individual contribution. There is no agreement in the literature about whether role strain exists for men in nursing; the impression that men are not suitable for nurses is a repeated theme within the literature. Role strain was studied by McLaughlin, Muldoon, and Moutray (2009) and they found that role strain and gender role labeling did exist in a 
quantitative, longitudinal study reviewing the retention of male and female students. Findings of some reviewed literature cited male preference of working in technical areas such as emergency, ICU, operating room, and anesthetics (Fisher, 2009; Meadus \& Twomey, 2011). The authors stated that the male tendency to such technical areas may be due to the fact that such roles appear more congruent with the masculine role. Working in such areas seems to decrease the extent of role strain, because not only less personal care is needed, but also nurses are less required to be dressed in traditional nurse uniforms (Stott, 2007).

Men make up 10\% of the nursing workforce in the United Kingdom and $6.6 \%$ of the three million nursing professionals in the United States of America (Grady, Stewardson, \& Hall, 2008). In Nigeria, the statistic is not that different, for instance, male students comprised $5.2 \%$ to $5.8 \%$ of the overall nursing students' population at the settings for the study. Everyone has the right to education despite gender differences; thus, nursing education should not be different for men and women. Public insights that nursing is a female-oriented role have been a major factor in the low numbers of men in the nursing field and continue to apply pressure on those in the profession (Keogh \& O'Lynn, 2007). Nursing institutions have responsibilities for ensuring that all qualified students are given the same opportunities for successfully obtaining the knowledge and skills necessary to become professional nurses (Keogh \& O’Lynn, 2007; Grady, Stewardson, \& Hall, 2008). Being a good nurse depends on innate biological characteristics and by inference, stereotypical feminine characteristics (Stroshine \& Brandl, 2011). The authors further explained that female nursing dominance has had a large impact on how the members of the profession are viewed by society and has determined what qualities are seen as integral to fulfilling the nursing role.

Nursing institutions should take the necessary steps to understand and resolve institutional practices or procedures that negatively impact the learning environment of male nursing students. Studies indicate an overall positive acceptance of men in nursing and how nursing profession have moved into greater acceptance of all gender (Meadus \& Twomey, 2011; McLaughlin, Muldoon, \& Moutray, 2010). However, the number of men in nursing does not reflect the number of men in the general populations. This different may stem from many causes but is of concern because a workforce that reflects the population is more likely to meet the health care needs of that population in a culturally sensitive manner. Hodes (2005) conducted an internet-based survey of 498 men specifically to identify the relationship between public perception and challenges for men who wanted to pursue nursing as a career. The challenges consisted of negative stereotypes (73\%), nursing being viewed as a traditionally female profession $(59 \%)$, and perception of other professions as more male appropriate $(53 \%)$. The study further found that, prior to embarking on a career in nursing, respondents perceived the profession as one traditionally dominated by females $(85 \%)$, and not the most appropriate profession for men to enter. It is not so common in Nigeria to have a male lactation consultant or a male nurse midwife. Male registered nurses are excluded from several forms of training and from certain positions. This might be due to rejection during maternity rotations in the nursing school, gender discrimination, poor networking, or just a lack of interest in this area (Meadus \&Twomey, 2011).

Adeniji, Akanni, \& Ekundayo (2015) conducted a study on gender differences in emotional labour among nurses in Osun State, Nigeria and they found out that emotional labour has been found to be an important aspect of many occupations, but is more prevalent in nursing. This is because, nurses are required to sustain the morale of patients, reassure those who are experiencing pain or anxiety, as well as offer comfort to relatives of the bereaved. Male nurses move towards areas such as the operating room and emergency care may be due to support from male physicians (Ellis et al., 2006). Scott reported that male students felt they were less likely to receive disciplinary action from their female nursing instructors when mistakes were made in the clinical setting (Hepzibha, 2010). The findings of Hodes research (2005) confirm the sense of achievement by men in nursing reporting that the overwhelming majority would pursue a nursing career all over again and would encourage their male friends to become nurses.

Hepzibha (2010) postulated that being labeled and stereotyped can result in barriers that can limit the choice of specialty for male student nurses. The nursing profession relies on nurse educators to educate and train future nurses who are fully capable and competent to meet the needs of a diverse and changing patient population. Nursing institutions have responsibilities for ensuring that nursing students receive training on the knowledge and skills necessary to become professional nurses (Meadus \& Twomey, 2011). Eventually, the goal is to increase the number of men in the nursing profession and ultimately change gender roles such that the most qualified individuals will be drawn to the profession regardless of gender. Nursing institutions should have a natural interest in making sure that gender bias and stereotypes are minimized in nursing institutions in order to provide equitable learning situations for all students as well as in creating a nursing workforce that reflects greater diversity in the nursing profession. This study examined gender discrimination and stereotypes in relation to men in nursing. The study also discussed role restrain among male student nurses in selected nursing institution in Lagos, Nigeria. 


\subsection{Kanter's Theory of Tokenism}

The theory of tokenism is an attempt to understand how an individual's identifying characteristics such as sex, race, ethnicity, age, or religion, impact his or her social and professional advancement when he or she is a minority within the group (Kanter, 1977). Kanter's (1977) tokenism theory argues that once tokens reach a tipping point of 15 percent representation in the workplace, they begin to experience fewer work place problems. The issue of gender inequities and the differential treatment of a subordinate group have been reviewed in the literature (Keogh \& O'Lynn, 2007; Meadus \& Twomey, 2011). As minorities within the field, the literature has shown that men have less influence within the nursing profession and have more difficulty successfully fulfilling the role or bringing their own ways of knowing and doing into accepted nursing practice. Kanter (1977) looked at issues of differential treatment in the work place when one gender group makes up a much greater proportion than the other. Kanter examined the experiences of women who were underrepresented in their organizations. The theory of tokenism that emerged from her research suggested that individuals whose social category is underrepresented in particular contexts will face negative experiences such as increased visibility and social isolation.

Kanter looked at how group dynamics impact the members of a gender minority within the work setting and established a framework for conceptualizing the processes that occur between dominants and tokens within these groups. Specifically, Kanter (1977) determined that a group that comprises less than $15 \%$ of their work group experienced three negative processes. First, the group in these token positions experienced enhanced visibility or a heightened sense of attention which can lead to increased performance pressures and silent emotional expression. Second, the differences between tokens dominants were exaggerated, creating a sense of social isolation among tokens. Third, tokens felt subject to constrained expectations and social roles consistent with gender stereotypes. Men are considered a token in nursing due to their low numbers in the nursing profession. Previous studies found that as members of a smaller gender group in nursing, men are not offered the same opportunities as women (Keogh \& O'Lynn, 2007; Meadus \& Twomey, 2011). Men in Nursing constitute a minority and as such are not exempted from the negative experiences faced by the social group that is underrepresented in a profession, this, in turn, discourages more men from going into nursing profession thereby, leaving the profession to be dominated by females. This may constitute a major factor in influencing the perception of secondary school students towards nursing as a career choice for men.

\section{Materials \& Methods}

The simple random sampling (balloting) method was used to select nursing institutions that were included in the study and convenience sampling method was used to select the respondents that partook in the study. The study population is male nursing students from 200 level-500 level of the selected nursing institutions. A questionnaire including measures of gender role identity and perceived gender appropriateness of careers was administered to 205 male student nurses from three nursing institutions. The questionnaire contained 28 items, which were obtained from the literature and piloted by a panel of nurse educators. A complete and comprehensive detail on the aims and implications of the study was given to the respondents. Informed consent was obtained while anonymity and confidentiality were maintained both during and after collection of data.

Data was analyzed using Statistical Package for Social Sciences (SPSS) Version 17. Variables were examined for normality before further analyses were conducted. Descriptive statistics were used to describe the demographic characteristics of the sample and major study variables. Associations between variables were examined using Chi-square.

\section{Results}

The results showed that $32 \%$ of the respondents had not experienced gender bias during nursing school, whereas $68 \%$ reported gender bias from the lecturers and the nursing staff. As professionals, $69 \%$ reported bias from the nursing staff and $31 \%$ of the physicians. Many of those surveyed had also perceived nursing as a profession for women. Fifty-six percent of those surveyed experienced difficulties in their nursing education. Fifty percent of male nursing students reported inequitable treatment by nursing faculty and fifty-two percent reported experienced difficulties during clinical posting. Seventy-eight percent of the participants also noted that nursing is overwhelmed by common misconceptions that emphasize the view that nursing is a female profession dominated by women and that man are not suited to it because they are not caring. Fifty-eight percent of the participants also emphasized that nursing educators refer to nurses using the word "she" and there is no discussion of the history of men in nursing. 
Table 1. Respondents experienced gender bias during nursing school, $\mathrm{N}=205$

\begin{tabular}{lll}
\hline Variable & Frequency & Percent \\
Positive perception of gender bias during nursing school & 140 & 68 \\
Negative perception of gender bias during nursing school & 65 & 32 \\
Total & $\mathbf{2 0 5}$ & $\mathbf{1 0 0 . 0}$ \\
\hline
\end{tabular}

A majority of the students surveyed experienced gender bias during nursing school

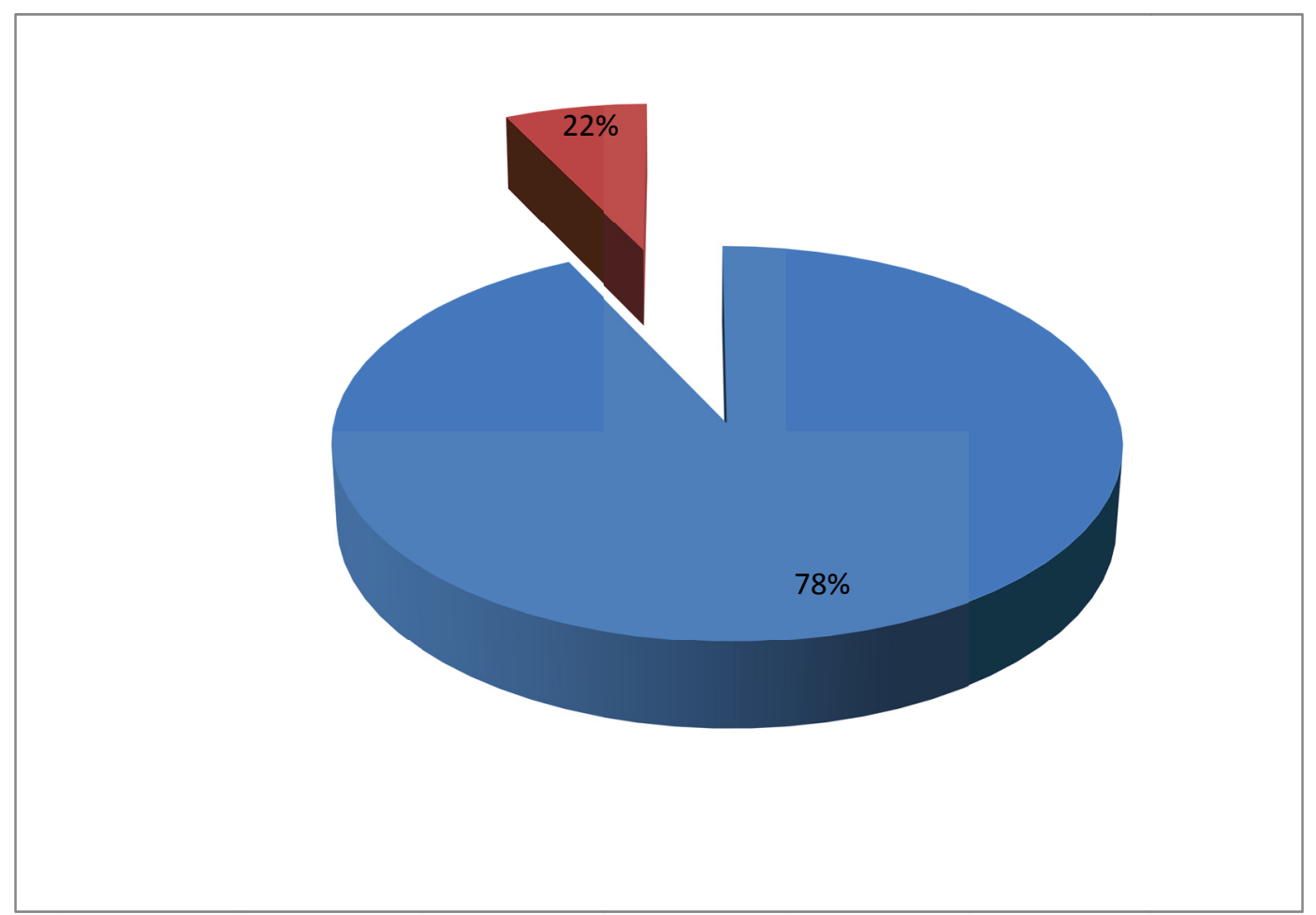

Figure 1. Common misconception that emphasizes the view that nursing is a female profession

\section{Discussion}

The findings from this study provided insight into when and what type of barriers men encountered in the nursing profession and add new depth to nurses understanding of the educational experience for men in nursing. It was the view of $56 \%$ of respondents that nursing was more appropriate for females because they are more caring and $44 \%$ said nursing was not appropriate for males because they were not caring enough. However in a study by McLaughlin et al (2010); attitude and perception towards men in nursing education in which the respondents consists of nursing and non-nursing students, majority of the respondents agreed that nursing is not a masculine type of career for male to pursue and there is a general perception that female nurses are more caring and nurturing when compared to male nurses. Nursing lecturers should be knowledgeable about gender discrimination. Gender discrimination should be considered an ethical issue and accurate information about origins of nursing stereotypes and the effects of those stereotypes on nursing students in training and practice should be well studied.

Advising is another method for neutralizing gender discrimination in nursing. Nursing department of various academic institutions should provide a forum for discussing problems that emerge during educational experiences (Loughery, 2008). Advising male students is more effective when the advisor is a male nurse who can relate to the student's issues ((McLaughlin et al., 2010). Nursing department of various academic institutions should admit more males into the institution. The Nursing and midwifery council should take measures to stop the media negative portrayal of nursing as a feminine profession and nurses being followers of doctors' order only. Nursing students should be trained to handle sensitive situations despite gender and be prepared to suppress feelings and concentrate on the task they are given to do. In addition, male nurses should be supported by their colleagues when providing intimate care to women clients and be able to talk freely about their experiences of providing intimate care.

\section{Nursing Implications}

This study has implications for nursing profession that address the current predicament in the nursing field caused by 
discrimination and social isolation that man face. The findings also have practical implication for the nursing education, practice, and research. The perception that nursing is a feminine profession is reinforced in the findings of this studies and so adequate awareness that nursing as a career provides them with the opportunity to help and care for others either as a male or a female. Therefore, Nursing and Midwifery council of Nigeria should develop a strategic plan which addresses the eradication of discrimination and racism in and by the nursing profession. This plan must be implemented, adequately funded and evaluated yearly and revised as necessary.

\section{Recommendations}

The following recommendations are made based on the conclusions of this study,

i. Nursing and Midwifery Council of Nigeria should encourage and promote gender diversity in nursing institutions

ii. Nursing as a career for both males and females should be strongly incorporated in career counseling in secondary schools in order to increase awareness and foster positive perception towards nursing.

iii. The Nursing and midwifery council should take measures to stop the media negative portrayal of nursing as a feminine profession and nurses being followers of doctors' order only

iv. The Nursing and midwifery council should foster the development of strategies to counter discrimination in the profession of nursing. Serve as a clearinghouse for information on this topic and distribute all relevant materials to state nurses associations and other professional nursing organizations.

v. Nursing institutions should encourage recruitment and retention of more male as faculty and students in schools of nursing.

vi. The Nursing and midwifery council should focus on multiple aspects of professional development that affect the participation of under-represented minorities in the nursing profession.

\section{References}

Adeniji, O., Akanni, A., \& Ekundayo, O. (2015). Gender difference in emotional labour among nurses in Osun State, Nigeria. Gender and Behaviour, 13(2), 6789-6794.

Ellis, D., Meeker, B., \& Hyde, B. (2006). Exploring men's perceived educational experiences in a baccalaureate program. Journal of Nursing Education, 45(12), 523-527.

Fisher, M. (2009). Being a chameleon: labor process of male nursing performing bodywork. Journal of Advanced Nursing, 65(12), 2668-2677. https://doi.org/10.1111/j.1365-2648.2009.05120.x

Grady, C., Stewardson, G., \& Hall, J. (2008). Faculty notions regarding caring in male nursing students. Journal of Nursing Education, 47(7), 314-323. https://doi.org/10.3928/01484834-20080701-05

Hepzibha, A. (2010). Upper secondary male students' perceptions of nursing as a career choice. International Journal for the Advancement of Sciences \& Arts, 1(1), 46-62.

Hodes, B. (2005). Men in nursing study. Retrieved September 2015 from http://aamn.org/docs/meninnursing2005survey.pdf

Kanter, R. (1977). Some effects of proportions on group life: Skewed sex ratios and responses to token women. American Journal of Sociology, 82, 965-990. https://doi.org/10.1086/226425

Keogh, B., \& O’Lynn, C. (2007). Male nurses' experience of gender barriers: Irish and American perspectives. Journal of Nursing Education, 32(6), 256-259. https://doi.org/10.1097/01.NNE.0000299478.64809.82

Lerardi, J., Fitzgerald, D., \& Holland, D. (2010). Exploring male students'educational experiences in an associate degree nursing program. Journal of Nursing Education, 49(4), 215-218. https://doi.org/10.3928/01484834-20091217-04

Love, K. (2010). The lived experience of socialization among African American nursing students in a predominantly white university. Journal of Transcultural Nursing, 21(4), 342-350. https://doi.org/10.1177/1043659609360711

Mark, L. (2008). Just How Male Are Male Nurses? Journal of Clinical Nursing, 17(10), 1327-1334. https://doi.org/10.1111/j.1365-2702.2007.02250.x

McLaughlin, K., Muldoon, O., \& Moutray, M. (2010). Gender, gender roles and completion of nursing education: a longitudinal study. Nurse Education Today, 30(4), 303-307. https://doi.org/10.1016/j.nedt.2009.08.005

Meadus, R., Twomey,J. (2011). Men student nurses: the nursing education experience. Nursing Forum, 46(4), 269-279. https://doi.org/10.1111/j.1744-6198.2011.00239.x 
Scriber, M. (2008). Warming the nursing education climate for traditional age learners who is male. Nursing Education Perspectives, 29, 143-150.

Shelton, E. (2012). A model of nursing student retention. International Journal of Nursing Education Scholarship, 9(1), 1-16. https://doi.org/10.1515/1548-923X.2334

Stott, A. (2007). Exploring factors affecting attrition of male students from an undergraduate nursing course; a qualitative study. Nurse Education Today, 27(4), 325-232. https://doi.org/10.1016/j.nedt.2006.05.013

Stroshine, M., \& Brandl, S.(2011). Race, gender, and tokenism in policing: An empirical elaboration. Police Quarterly, 14(4), 344-365. https://doi.org/10.1177/1098611111423738

\section{Copyrights}

Copyright for this article is retained by the author(s), with first publication rights granted to the journal.

This is an open-access article distributed under the terms and conditions of the Creative Commons Attribution license which permits unrestricted use, distribution, and reproduction in any medium, provided the original work is properly cited. 